Methods A project methodology approach is being used to plan 'I Experience VR':

- Staff training and VR Champion recruitment

- Evaluation of patient experiences

- Enhancements to patient well-being using VR

- Commissioning further VR films

- Expansion of partnership consortium

- Creative marketing.

Results

- 20 VR Champions trained across all sectors of hospice care

- All patients reported feeling more relaxed and some who were in pain reported a reduction in pain 'Amazing'; 'I feel like I am there'; 'I was not aware of the pain in my hands and wrists'; 'I so enjoyed being back by the sea'

- Commissioned four films, one being a hospice tour aimed at reducing anxiety before visiting a hospice

- Four hospices have joined the partnership consortium, with others interested.

\section{P-140 ADAPTED TAI CHI IN PALLIATIVE CARE - THE IMPACT ON WELL-BEING AND QUALITY OF LIFE}

${ }^{1}$ Andrew Bradshaw, ${ }^{2}$ Samantha Greenwood, ${ }^{2}$ Lynne Yeadon, ${ }^{2}$ Kate Eagle. 'Leeds University, Leeds, UK; ${ }^{2}$ Sue Ryder Wheatfields Hospice, Leeds, UK

10.1136/bmjspcare-2018-hospiceabs. 165

Background Living with advanced, incurable disease presents multifaceted adversities which negatively impact on various domains of well-being (McCaffrey, Bradley, Ratcliffe et al., 2016). Whilst initial evidence is promising (Wang, Collet \& Lau, 2004; Zeng, Luo, Xie et al., 2014) the role that mindful movement therapies may have on ameliorating patients' experiences and quality of life (QoL) is not well understood.

Aim Explore how participation in Tai Chi impacted on participants' experiences of QoL within the context of multi-disciplinary day-therapy hospice care.

Methods A focused ethnography (Wall, 2014) was used to guide data collection in this study. Data was collected with patients $(n=19)$ with advanced, incurable disease who took part in Tai Chi sessions offered at Wheatfields Hospice. Over a six month period, semi-structured interviews, participant observations, and informal conversations were used in order to gain a multi-dimensional, embodied and nuanced understanding of patients' perceptions of their QoL across four broad domains of well-being (i.e., physical, psychological, social, and spiritual). Data was analysed using a thematic framework approach (Ritchie, Lewis, Nicholls et al., 2013).

Results Two overarching themes (each accompanied by two sub-themes) captured participants' experiences of their QoL through participation in the hospice-based Tai Chi programme, including:

i. Mind-body respite (sub-themes: being present in the moment and embodied peace)

ii. Social engagement (sub-themes: meaningful social connections and mutual empathy and reciprocal support).

Conclusion These findings provide evidence for the value of mindful movement therapies (such as Tai Chi) in serving as a non-pharmacological adjunct to conventional palliative care treatment in improving the QoL of patients with advanced, incurable disease regardless of disease type.

\section{P-141 REIKI TRAINED NURSES: INTEGRATING ENERGY THERAPY INTO PALLIATIVE CARE FOR PATIENTS, CARERS AND STAFF}

Nicky Forbes. Eden Valley Hospice, Cumbria, Carlisle, UK

10.1136/bmjspcare-2018-hospiceabs. 166

Background Reiki therapy can be delivered 'Anytime, Anyplace, Anywhere' - no equipment, towels or oils required. With minimal contraindications, using touch or non-touch, Reiki is a gentle, effective therapy for palliative patients and carers. Research, including a Cochrane review (2008) for pain reduction, supports the benefits of Reiki for side effects of nausea, anxiety, digestion issues and irritability.

Aim To initiate a staff training project to integrate Reiki within overall care in the day hospice, in-patient unit and the children's hospice. Funding of $£ 4700$ was received for this project from the Hadfield Trust. Reiki therapist post was pump-funded by the Sam Buxton Sunflower Healing Trust for 2.5 years.

Methods Four staff nurses and two activity coordinators trained to Reiki II practitioner level. Involving eight contact days (64 hours), four Reiki share sessions (eight hours) and weekly at home practice over 11 months. Education sessions across the hospice raised awareness of the therapy and staff training project. New working practice on the wards introduced, including MYCAW evaluations and self-care tools for patients, carers and staff.

Results Trained staff now provide Reiki within their general roles on the wards, enabling Reiki to be available at point of need, day or night. Staff have been providing Reiki since April 2018, so results continue to be compiled. In two months, 70 additional patients, carers and staff have received Reiki from staff practitioners. Fundraising continue to explore future opportunities to train additional medical staff.

Conclusion With an increased number of patients benefiting from Reiki, plus boosted awareness stimulating referrals, we believe the training has made a significant difference to the quality of care - emotionally, physically and spiritually. Qualitative and quantitative data gathering continues.

\section{P-142 EVALUATION OF A NEW PORTABLE ULTRASOUND FACILITY AT COUNTESS MOUNTBATTEN HOUSE HOSPICE}

Anna Hume. Countess Mountbatten House, Southampton, UK

10.1136/bmjspcare-2018-hospiceabs. 167

Background It has been standard practice for all patients to have US prior to paracentesis. This involved:

- Ambulance transfer to/from Acute Hospital in Southampton $[\mathrm{SGH}]$

- Nurse escort

- Admin time

- Cost average $=£ 600$ per patient

- Increased length of stay by 4-7 days, awaiting scan at SGH

- Poor patient experience.

$50 \%$ of our patients died within 10 days of paracentesis, indicating their general frailty and the importance of short admission. 
Intervention A portable ultrasound machine was purchased by Countess Mountbatten House Hospice at £5780. Suitable training was undertaken by the author at $£ 450$.

Results 50 scans were performed over one year:

2 at home: both no ascites [died at home within seven days]

17 in OPA: 8 admitted for paracentesis

9 no ascites [ 1 U.retention - catheter inserted ]

31 in IPU: 17 ascitic drains placed

9 no ascites

5 catheters inserted for U.retention

Outcomes

- 11 admissions avoided

- 31 transfers avoided [31x £600] $=£ 18600$

- 124 bed days saved [31x4 minimum wait for scan at $£ 294$ per day $]=£ 36456$

Patient experience improved:

- Unnecessary admission avoided

- Transfer avoided

- Faster relief of symptoms

- Reduced length of stay.

\section{P-143 DEVELOPMENT OF THE PORTABLE ULTRASOUND FACILITY AT COUNTESS MOUNTBATTEN HOUSE HOSPICE}

Anna Hume. Countess Mountbatten House, Southampton, UK

\subsection{6/bmjspcare-2018-hospiceabs. 168}

Background Facilitating preferred place of care and death (PPC/PPD) are important aspects of good palliative care. Disease progression, increasing frailty and reduced mobility are associated with increased incidence of thrombosis (DVT) and urinary retention causing distress and sometimes admission. The development of ascites is another indicator of general frailty $(50 \%$ died within 10 days of paracentesis) and the importance of short admission. The development of our portable ultrasound facility was envisaged as a useful tool to improve delivery of care and assist achievement of PPC/PPD.

Intervention Availability of the portable ultrasound machine to all Countess Mountbatten House teams to identify/exclude ascites, DVT, Urinary retention and to assist transfusion/hydration when cannulation is difficult.

Results 50 scans were performed over eight months:

4 at home: 4 no ascites (2 died at home within 9 days, 1 U.retention - catheter inserted, 1 cellulitis with indwelling drain - admitted)

19 in OPA: 8 ascites - admitted for paracentesis

7 no ascites [2 GB abscess, 1 U.retention]

2 DVT confirmed [anticoagulated at home]

2 DVT excluded

27 in IPU: 11 ascitic drains placed

7 no ascites [5 U.retention - catheter inserted]

5 DVT confirmed [anticoagulant started]

3 assisted cannulations for transfusion

1 pericardial effusion (transferred to cardiology).

\section{Outcomes}

- 14 admissions avoided

- 26 transfers for scan or central line avoided
- 4 units of blood not wasted

- 104 bed days saved [26 $\times 4$ days minimum wait for scan]

Patient experience improved:

- Unnecessary admission avoided

- Transfer avoided

- Faster relief of symptoms

- Reduced length of stay.

\section{P-144 PROGRESS AND DEVELOPMENT FOLLOWING AN AUDIT OF ROUTINE WEIGHING ON A HOSPICE INPATIENT UNIT}

Jan Codling, Amanda Connors, Imerjit Manak, Jennie Pickard, Alison Phippen, Samantha Kay, David Waterman. St Ann's Hospice, Greater Manchester, UK

\subsection{6/bmjspcare-2018-hospiceabs.169}

Background A previous audit highlighted that an absence of weighing patients on admission potentially limited ability to meet best practice standards for medicine management and nutritional assessment. A survey also highlighted a staff misconception that patients do not like being weighed. Clinical staff now receive training demonstrating the inaccuracy of estimating body weight and routine weighing was introduced for inpatients and daycare patients.

Aim To measure compliance to weighing daycare patients. To maintain the change in practice of weighing patients by providing regular feedback, promoting clinical ownership and responding to staff views on how to improve the process.

Method Inpatients: A monthly audit is conducted by non-registered nurses who are often the person who is tasked with weighing patients on the ward. The audit measures if the patient's weight was recorded on their medicine chart within three days of admission.

Daycare: An audit measuring if patients were weighed within two visits and easily accessible on the patient's electronic record was conducted by a medical student six months after routine weighing was introduced for daycare patients. Results

Abstract P-144 Table 1 Results of the Inpatient Weighing Audit

\begin{tabular}{lcc}
\hline Inpatients & $\begin{array}{c}\text { Weight recorded on medicine } \\
\text { chart }\end{array}$ & $\begin{array}{c}\text { Weighed within } 3 \text { days of } \\
\text { admission }\end{array}$ \\
\hline $\begin{array}{l}\text { October } \\
2017\end{array}$ & $62 \%$ & $61 \%$ \\
March 2018 & $89 \%$ & $75 \%$ \\
\hline
\end{tabular}

Abstract P-144 Table 2 Results of the Day Care Weighing Audit

\begin{tabular}{lcccc}
\hline Daycare & $\begin{array}{c}\text { Patients } \\
\text { weighed }\end{array}$ & $\begin{array}{c}\text { Weighed } \\
\text { within 2 visits }\end{array}$ & $\begin{array}{c}\text { Weight recorded on } \\
\text { electronic record }\end{array}$ & $\begin{array}{c}\text { Weight accessible } \\
\text { via read code }\end{array}$ \\
\hline $\begin{array}{l}\text { May } \\
2018\end{array}$ & $95 \%$ & $77 \%$ & $77 \%$ & $74 \%$
\end{tabular}

Conclusions Both audits demonstrated improvements in compliance to weighing patients. During the inpatient audit, it became apparent that some patients have a long hospice stay and need to be re-weighed a minimum of monthly. 